DOI: $10.33947 / 1981-7428-v 18 n 1-4024$

\title{
O PLÁSTICO COMO VILÃO DO MEIO AMBIENTE
}

\section{THE PLASTIC AS A VILLAIN OF THE ENVIRONMENT}

\author{
Márcio Magera Conceição1', Joelma Telesi Pacheco Conceição, Fabricio Bau Dalmas², \\ Alessandro Marco Rosini ${ }^{3}$
}

\begin{abstract}
RESUMO
Este artigo trabalha uma revisão narrativa de algumas literaturas bibliográficas e eletrônicas, sobre a problemática do plástico no meio ambiente e seu descarte inadequado. $\mathrm{O}$ objetivo é facilitar ao leitor adquirir e atualizar o conhecimento sobre a temática específica em curto espaço de tempo, porém não possui metodologia que permita a sua reprodução, mas é considerado uma narrativa qualitativa pela qualidade das fontes referenciadas. Nos dias atuais a mídia vem evidenciando a poluição provocada no meio ambiente pelos resíduos do plástico e suas consequências para gerações futuras. Desde o seu surgimento no final do século XIX até os dias atuais este polímero vem enfrentando sérias contradições, de um lado as empresas de transformação que dependem deles para sua produção, de outro lado seu descarte de forma inapropriada, ocorrendo em grande volume nos oceanos, fator que vem provocando retaliações por grupos de consumidores conscientes, acendendo um alerta para a comunidade cientifica mundial. Tais consequências podem diminuir, caso os governos, empresas e consumidores tomassem posições homogêneas em relação ao reuso e substituição do plástico por outra matéria prima de igual característica. Portanto, tais ações serão evidenciadas neste artigo, o que demostrará que temos soluções para o problema, mas isto passa por uma universalização das vontades políticas.
\end{abstract}

PALAVRAS-CHAVE: Sustentabilidade. Gestão Ambiental. Impacto Ambiental. Indústria do Plástico.

\section{ABSTRACT}

This article presents a narrative review of some bibliographic and electronic literature on the problem of plastic in the environment and its inappropriate disposal. The goal is to facilitate the reader to acquire and update knowledge about the specific theme in a short time, but has no methodology that allows its reproduction, but is considered a qualitative narrative by the quality of the referenced sources. Nowadays the media has been highlighting the pollution caused by plastic waste on the environment and its consequences for future generations. From its emergence in the late nineteenth century to the present day this polymer has been facing serious contradictions, on the one hand processing companies that depend on it for their production, on the other side its improper disposal, occurring in large volumes in the oceans, a factor that has been causing retaliation by conscious consumer groups, igniting a warning to the worldwide scientific community. Such consequences may diminish if governments, businesses and consumers take homogeneous positions on the reuse and replacement of plastic with another raw material of similar character. Therefore, such actions will be highlighted in this article, which will show that we have solutions to the problem, but this involves a universalization of political wills.

KEYWORDS: Sustainability. Environmental Management. Environmental Impact. Plastic Industry

1 Doutor. Docente do Mestrado em Análise Geoambiental da Universidade UNG

2 Doutor. Docente do Mestrado em Análise Geoambiental da Universidade UNG

3 Doutor. Docente da Universidade Anhanguera de São Paulo 


\section{INTRODUÇÃO}

Este artigo traz um tema muito evidenciado pela mídia nos dias atuais, a poluição que os plásticos estão provocando no meio ambiente e suas consequências para as gerações futuras. Desde o seu surgimento no final do século XIX até os dias atuais este polímero vem enfrentando serias contradições, de um lado as empresas de transformação que não conseguem produzir sem ele, mas o seu descarte de forma inapropriada no meio ambiente vem provocando retaliações por grupos de consumidores conscientes e o volume que está sendo descartado nos oceanos acende um alerta para a comunidade cientifica mundial (WWF / Banco Mundial (What a Waste 2.0: A Global Snapshot of Solid Waste Management to 2050). Os milhões de toneladas despejados anualmente no meio ambiente vem trazendo consequências irreversíveis para a vida no planeta Terra. A vida curta de muitas embalagens e a obsolescência programada são fatores que agravam ainda mais o futuro do plástico como uma matéria prima de uso universal e irrestrito. O Brasil é o quarto maior produtor mundial de plástico e ainda não possui políticas voltadas ao controle e reciclagem deste resíduo que continua presente nas prateleiras dos mercados mundiais. Talvez um alinhamento entre os principais países consumidores e produtores poderia levar a criação de ações restritivas universais em relação ao seu uso e ao seu descarte de forma mais apropriada, com menor agressão ao Meio Ambiente.

\section{A IMPORTÂNCIA DO PLÁSTICO NO SETOR PRODUTIVO}

Desde a sua criação, que ocorreu no final do século XIX, o plástico faz parte da vida cotidiana das pessoas no planeta Terra. Por todo o lado que você olhe tem sua presença; na sua casa, no trabalho, na sua roupa, no transporte e até na sua alimentação, enfim, no dia a dia das pessoas, e seu consumo só aumenta em escala exponencial, segundo a ONU. Outro fator não menos importante é a presença de microplásticos no ambiente e nos alimentos, o que podem causar sérios danos a fauna, flora e para a saúde pública. Pesquisadores britânicos descobriram micropartículas de plástico no intestino de camarões e peixes que habitam as regiões oceânicas mais profundas da Terra. A poluição humana não se limita à superfície dos mares, já está presente em todo o globo terrestre (Globalgarbag.com.br, 2018), contaminando consequentemente toda a cadeia alimentar.
Estima-se que já foram produzidos mais de 9 bilhões de toneladas de plásticos, e dois terços já foram parar no lixo, enquanto um terço ainda continua sendo utilizado. Deste total somente 10\% aproximadamente foram reciclados, ou reutilizados para novas funções ou aplicações. E o mais preocupante é que anualmente são jogados mais de 8 milhões de toneladas nos oceanos, trazendo uma série de consequências para a vida marítima, a pesca e ao turismo, fatos que ainda não temos os contornos definidos, contando somente com uma leitura superficial dos especialistas que já mostram que neste ritmo, em poucas décadas, teremos mais plásticos do que peixes nos oceanos. (Revista Pesquisa FAPESP, 281, ano 2019). Este polímero é originário de materiais fósseis, do petróleo, e sua invenção trouxe para a sociedade um avanço na área da saúde, alimentação e tecnologia, portanto, foi fundamental para a evolução do planeta, mas paradoxalmente pode ser sua ruina se não controlada sua produção e seu reuso no setor industrial. Eis, o desafio para as futuras gerações, conviver com este mal ou substitui-lo por algo menos danoso.

A sociedade moderna vem apresentando uma necessidade cada vez maior do consumo e descarte para manter a economia gerando emprego e renda, $e$ neste cenário, o plástico é fundamental para alimentar o dia a dia do mercado. É difícil pensar a vida cotidiana sem a presença dele, apesar da sua invenção ser relativamente recente. Sua popularização ocorreu na década de 50, após o final da Segunda Guerra Mundial. Foi assim que o plástico passou a ser valorizado e a pertencer a um novo estilo de vida, mais voltada a obsolescência programada dos produtos (MAGERA, 2015). Imaginem um celular, um carro, um avião sem plástico, como seriam? Portanto, sua participação na evolução tecnológica foi e é fundamental, mas como iremos lidar com seus resíduos será o grande desafio das novas civilizações. Alguns físicos como o Dr. Munir Salomão Skaf, da Universidade de Campinas - UNICAMP, disse: "o baixo custo e a estabilidade dos plásticos diante dos processos naturais de degradação o tornaram onipresente no mundo, mas ressalva que essas mesmas propriedades fazem dele um sério agente poluidor por não se degradar facilmente no ambiente" (Revista Pesquisa FAPESP, VOLUME 281, pg.31). Estudos realizados pela Faculdade de Química da Unicamp, acreditam que alguns tipos de plásticos levam 200 anos para se decompor na natureza, o que por si só já mostra que seu uso precisa ser equalizado e seu reuso obrigatório. A pesquisa foi realizada no curso de química e 
envolveu discentes e docentes por 3 anos, utilizando polímeros e seus derivados.

Alguns tipos de plásticos têm uma vida muito efêmera, ou seja, muito curta no mercado, mais de $40 \%$ da produção destes polímeros não chegam a ficar mais de 2 meses nas prateleiras e já tem um destino certo, após o uso, que são os aterros sanitários e oceanos (MAGERA, 2015). A natureza não está conseguindo absorver toda nossa produção o que levou alguns países a tornarem o plástico como um vilão do século XXI - Alemanha, Japão, Canadá. Mas, há algumas ações que poderiam ser adotadas pelos governos e empresas, tais como: a substituição por novos materiais com características similares ao plástico, coleta seletiva e reuso obrigatório, diminuição da obsolescência programada de alguns produtos, uma fiscalização maior no descarte deste resíduo, responsabilização das empresas produtoras de plástico pela sua logística reversa. Segundo a WWF, Science Advances, 2017, a produção global de plástico pode chegar a 550 milhões de toneladas em 2030, com um volume $40 \%$ superior ao nível atual, portanto percebe-se que passou da hora dos governos, entidades representativas do meio ambiental, empresas e organismos internacionais de prospectarem um plano de substituição desta matéria prima que poderá levar o planeta a um caos se não controlada sua produção e logística, e suas consequências para a vida no planeta Terra poderão ficar fora do controle.

O Brasil é o quarto maior produtor de resíduos plástico do mundo (WWF, 2016), com 11,3 milhões de toneladas por ano, superados apenas pelos Estados Unidos, China e Índia, conforme quadro 1. Deste total somente $1,28 \%$ foi reciclado, um dos menores índice do mundo, sendo que a média global gira em entorno de 9\%, segundo o Banco Mundial, dados do ano de 2018. Este quadro é mais relevante quando se refere ao Brasil, visto que mais de $40 \%$ dos resíduos domésticos do país são despejados em lixões a céu aberto, segundo o IBGE, (2017). Sem infraestrutura adequada de saneamento básico, o país sofre com este tipo de poluição, visto que boa parte dos resíduos domésticos vão parar nas periferias das grandes cidades brasileiras, a onde o Estado não chega com seus investimentos em políticas públicas voltada ao Meio Ambiente saudável. Segundo nossos governantes, não há recursos para investir no tratamento dos resíduos domésticos, mas de acordo com a Lava Jato - A Operação Lava Jato é um conjunto de investigações em andamento pela Polícia Federal do Brasil, que cumpriu mais de mil mandados de busca e apreensão, de prisão temporária, de prisão pre- ventiva e de condução coercitiva, visando apurar um esquema de lavagem de dinheiro que movimentou bilhões de reais em propina - com os bilhões que foram roubados dos cofres públicos poderíamos ter uma melhor infraestrutura no país, inclusive com aplicações dos recursos em saneamento básico.

Quadro 1. Quantidades de lixo produzidas por alguns países e a relação produção/reciclagem.

\begin{tabular}{|c|c|c|c|c|}
\hline Pais & $\begin{array}{c}\text { Total de lixo } \\
\text { plástico } \\
\text { gerado }\end{array}$ & $\begin{array}{c}\text { Total inci- } \\
\text { nerado }\end{array}$ & $\begin{array}{c}\text { Total reci- } \\
\text { clado }\end{array}$ & $\begin{array}{c}\text { Relação } \\
\text { produção e } \\
\text { reciclagem }\end{array}$ \\
\hline $\begin{array}{c}\text { Estados } \\
\text { Unidos }\end{array}$ & 70.782 .577 & 9.060 .170 & 24.490 .772 & $34.60 \%$ \\
\hline China & 54.740 .663 & 11.988 .226 & 12.000 .331 & $21.92 \%$ \\
\hline Índia & 19.311 .633 & 14.544 & 1.105 .677 & $5.73 \%$ \\
\hline Brasil & 11.355 .220 & 0 & 145.043 & $1.28 \%$ \\
\hline Indonésia & 9.885 .081 & 0 & 362.070 & $3.66 \%$ \\
\hline Rússia & 8.948 .132 & 0 & 320.088 & $3.58 \%$ \\
\hline Alemanha & 8.286 .827 & 4.876 .027 & 3.143 .700 & $37.94 \%$ \\
\hline Reino Unido & 7.994 .284 & 2.620 .394 & 2.513 .856 & $31.45 \%$ \\
\hline Japão & 7.146 .514 & 6.642 .428 & 405.834 & $5.68 \%$ \\
\hline Canadá & 6.696 .763 & 207.354 & 1.423 .139 & $21.25 \%$ \\
\hline & & & & \\
\hline
\end{tabular}

Fonte: WWW/Banco Mundial (What a Waste 2.0: A global Snapshot of Solid Waste Manegemante to 2050), adaptado.

\section{CONSIDERAÇÕES FINAIS}

O Brasil precisa investir em políticas voltadas às técnicas de reciclagem e a economia circular, envolvendo todos os atores que contemplam este cenário, a indústria de transformação, o governo, os consumidores e as empresas ligadas à coleta de resíduos. A economia circular é um conceito novo na reutilização, recuperação e reciclagem de materiais pós uso. Mas estas políticas ainda enfrentam fortes resistências por razões que englobam o baixo custo das matérias primas, a alto custo da logística para o transporte e as empresas financiadoras de campanhas públicas, sem falar das licitações viciadas que predominam em grande parte dos acordos governamentais nas obras públicas.

O governo deveria criar leis de incentivos fiscais e dinheiro a fundo perdido para a implantação de plantas recicladoras que poderiam ser espalhadas pelo país com capacidade produtiva que levasse o mercado a acreditar mais no potencial deste segmento, pois segundo Sabetai Calderoni, o Brasil perde por ano mais de 10 bilhões de dólares com a não reciclagem dos resíduos domésticos. Mas nem tudo são notícias ruins, cientistas da Universidade Estadual do Colorado, nos Estados Unidos, desco- 
briram através de experimentos científicos um tipo de plástico que pode ser convertido ao seu estado original e reciclado infinitas vezes, sem deixar resíduos, mas isto ainda está em fase de teste. Muitas cidades pelo mundo já estão proibindo as sacolas plásticas, o uso de canudos, adotando ações isoladas, mas importantes para conterem o crescimento desenfreado do uso deste polímero que teve e tem um papel importante no cotidiano das pessoas, mas que também hoje é seu maior pesadelo.

Neste contexto, o melhor é o homem não querer enfrentar a fúria da mãe natureza, ou como relatou o físico Marcelo Gleiser "Todo mundo já teve alguma experiência assustadora com o clima: uma tempestade devastadora, rios em cheia, desabamentos, ressacas violentas...por experiência própria ou por notícias de outros países, cansamos de ver que, quando a Natureza resolve demonstrar seus poderes, nossos recursos e ingenuidade, mesmo que úteis, raramente são suficientes". Portanto, acredito que fomos nós que fizemos este mundo deste jeito, e podemos sim, mudar nosso padrão de consumo, se a vontade humana for guiada pelo coração e o amor ao próximo, e quando digo próximo estou me referindo a toda forma de vida no planeta Terra. Vamos fazer isto enquanto há tempo, caso contrário a Mãe Natureza irá nos ensinar de forma dolorosa a encontrarmos soluções.

\section{REFERÊNCIAS}

CALDERONI, Sabetai. Os bilhões perdidos no lixo. São Paulo: Editora Humanitas, USP, 2003.

GLEISER, Marcelo. 0 caldeirão azul, o universo, o homem e seu espírito. Rio de Janeiro: Editora Record, 2019.

MAGERA, Marcio. Os caminhos do lixo. 2. ed. Campinas, SP: Editora. Átomo Alinea, 2015.

VASCONCELOS, Yuri. Planeta Plástico. Revista Pesquisa FAPESP, São Paulo, n. 281, jul. 2019. WWF / Banco Mundial (What a Waste 2.0: A Global Snapshot of Solid Waste Management to 2050

\section{SITES CONSULTADOS}

Disponível em: https://www.wwf.org.br/ . Acesso em: 14 out 2019.

Disponível em: https://www.worldbank.org/pt/country/brazil. Acesso em: 14 out 2019.

Disponível em: http://globalgarbag.com.br. Acesso em: 18 out 2019.

Disponível em: http://unicamp.br. Acesso em: 17 out 2019.

Disponível em: https://nacoesunidas.org/. Acesso em: 15 out 2019.

Disponível em: http://www.mpf.mp.br/grandes-casos/ caso-lava-jato/entenda-o-caso.

Acesso em: 15 out 2019.

Disponível em: http://globalgarbag.com.br. Acesso em: 16 out 2019.

Disponível em: https://www.mma.gov.br/. Acesso em: 14 out 2019. 